\title{
$\beta$-Galactosidase with transgalactosylation activity from Lactobacillus fermentum K4
}

\author{
G. X. Liu, ${ }^{*}$ J. Kong,† W. W. Lu,† W. T. Kong,† H. Tian, ${ }^{*}$ X. Y. Tian, ${ }^{*}$ and G. C. Huo*1 \\ *State Key Laboratory of Dairy Science, Northeast Agricultural University, Ministry of Education, No. 59 Mucai Street, Xiangfang District, Harbin, \\ Heilongjiang Province, 150030, China \\ †State Key Laboratory of Microbial Technology, Shandong University, No. 27 Shanda South Road, Jinan, Shandong Province, 250100, China
}

\section{ABSTRACT}

The LacLM $\beta$-galactosidase of Lactobacillus fermentum $\mathrm{K} 4$ is encoded by 2 consecutive genes, lacL (large subunit) and lacM (small subunit), that share 17 overlapping nucleotides. Phylogenetic analysis revealed that this enzyme was closely related to other Lactobacillus $\beta$-galactosidases and provided significant insight into its common and distinct characteristics. We cloned both the lacL and lacM genes of L. fermentum K4 and heterologously expressed each in Escherichia coli, although the recombinant enzyme was only functional when both were expressed on the same plasmid. We evaluated the enzymatic properties of this species-specific LacLM $\beta$-galactosidase and discovered that it acts as both a hydrolase, bioconverting lactose into glucose and galactose, and a transgalactosylase, generating prebiotic galacto-oligosaccharides (GOS). The recombinant $\beta$-galactosidase showed a broad $\mathrm{pH}$ optimum and stability around neutral $\mathrm{pH}$. The optimal temperature and Michaelis constant $\left(K_{m}\right)$ for the substrates $o$-nitrophenyl- $\beta$-D-galactopyranoside and lactose were, respectively, $40^{\circ} \mathrm{C}$ and 45 to $50^{\circ} \mathrm{C}$ and $1.31 \mathrm{mM}$ and $27 \mathrm{mM}$. The enzyme activity was stimulated by some cations such as $\mathrm{Na}^{+}, \mathrm{K}^{+}$, and $\mathrm{Mg}^{2+}$. In addition, activity was also enhanced by ethanol $(15 \%$, wt/vol). The transgalactosylation activity of L. fermentum K4 $\beta$-galactosidase effectively and rapidly generated GOS, up to $37 \%$ of the total sugars from the reaction. Collectively, our results suggested that the $\beta$-galactosidase from $L$. fermentum $\mathrm{K} 4$ could be exploited for the formation of GOS.

Key words: $\beta$-galactosidase, Lactobacillus fermentum, lactose, galacto-oligosaccharides

Received April 24, 2011.

Accepted September 5, 2011.

${ }^{1}$ Corresponding author: gchuo58@126.com

\section{INTRODUCTION}

The carbohydrate-active enzymes (CAZymes) are divided among 5 functional classes: glycoside hydrolases (GH), glycosyltransferases, polysaccharide lyases, carbohydrate esterases, and carbohydrate-binding modules (Cantarel et al., 2009). The $\beta$-galactosidases ( $\beta$-gal, EC 3.2.1.23) belong to 4 different GH families (GH1, GH2, GH35, and GH42; http://www.cazy.org/) and catalyze the hydrolysis and the transgalactosylation of $\beta$-D-galactopyranoside substrates such as lactose. $\beta$-Galactosidases are widely distributed throughout nature and have been characterized in animals, plants, and microorganisms, including bacteria, fungi, and yeast. The $\beta$-gal from Escherichia coli has been particularly well described because of the universal application of the lactose operon as a molecular tool. Furthermore, the transgalactosylation activity of $\beta$-galactosidases has gained considerable attention for its ability to produce galacto-oligosaccharide (GOS) prebiotics (Otieno, 2010; Park and Oh, 2010).

Galacto-oligosaccharides are enymatically produced upon lactose conversion, and they vary in saccharide chain length (between 2 and 8 monomeric units) and the types of linkages between the units. Recently, however, certain invariable characteristics were described. The saccharide chain is composed of a single terminal glucose, galactose monosaccharides, and disaccharides comprising 2 galactose units (Tzortzis and Vulevic, 2009). Industrial processes aimed at producing lowlactose or lactose-free items are concerned with undesirable GOS byproducts, for fear of unknown side effects that may stimulate symptoms of lactose intolerance. However, GOS have demonstrated beneficial effects that are distinct from lactose. The GOS can increase the numbers of Bifidobacterium strains and other probiotics (Onishi and Tanaka, 1995; Rabiu et al., 2001; Rastall and Maitin, 2002; Macfarlane et al., 2008) and contribute to metabolic activity of colon microbiota (Knol et al., 2005). As such, GOS have been proposed as an emerging special class of prebiotics and have gained popularity as supplemental components to 
Table 1. Bacterial strains and plasmids included in this study

\begin{tabular}{|c|c|c|}
\hline Strain or plasmid & Characteristic $^{1}$ & Source \\
\hline Lactobacillus fermentum K4 & Isolated from Chinese traditional dairy products & This work \\
\hline Escherichia coli Origami B (DE3) & $\begin{array}{l}\mathrm{F}^{\prime} \text { omp T hsd } S_{\mathrm{B}}\left(\mathrm{r}_{\mathrm{B}}^{\prime} \mathrm{m}_{\mathrm{B}}^{\prime}\right) \text { gal dcm lacY1 ahpC(DE3) gor522:: Tn } 10 \\
\text { trxB }\left(\operatorname{Kan}^{\mathrm{r}} \text {, Tet }{ }^{\mathrm{r}}\right) \text {; derived from a LacZY mutant of DE3 and carries } \\
\text { trxB } \text { /gor mutations for cytoplasmic disulfide bond formation }\end{array}$ & Novagen, Germany \\
\hline \multicolumn{3}{|l|}{ Plasmid } \\
\hline pET-22b $(+)$ & $\mathrm{Amp}^{\mathrm{r}}, 5.5 \mathrm{~kb}, \mathrm{C}$-terminal His-Tag. $\mathrm{T} 7$ promoter/lac operator, pelB leader & Novagen, Germany \\
\hline pDuetL & $\mathrm{Amp}^{\mathrm{r}}, 7.3 \mathrm{~kb}$, pET Duet-1 derivative with lacL gene inserted after His-Tag & This work \\
\hline pDuetLM & $\begin{array}{l}\text { Amp }{ }^{\mathrm{r}}, 8.2 \mathrm{~kb} \text {, pET Duet-1 derivative with lacL gene inserted } \\
\text { after His-Tag and lacM gene inserted before S-Tag }\end{array}$ & This work \\
\hline
\end{tabular}

${ }^{1} \mathrm{Amp}^{\mathrm{r}}=$ ampicillin resistant; $\operatorname{Kan}^{\mathrm{r}}=$ kanamycin resistant; $\operatorname{Tet}^{\mathrm{r}}=$ tetracycline resistant; MCS $=$ multiple clone site.

infant formula powder, wherein they replicate the oligosaccharide effect of human milk (Torres et al., 2010). It is now believed that combining prebiotic GOS with probiotics in food sources will strongly benefit overall human health.

Lactic acid bacteria (LAB) are an established and crucial component of modern dairy processing and the food industry. The most common species applied are from the genera Lactobacillus, Lactococcus, Bifidobacterium, and Streptococcus. Lactobacillus fermentum is a heterofermentative LAB that acts within a broad range of environmental niches, including dairy, meat, cereal, and vegetable fermentations, and even in the human gastrointestinal tract (Walter, 2008). The probiotic properties of some L. fermentum strains have been described, such as that of the ME-3 strain, which is also considered to elicit a prebiotic effect (Calderon Santoyo et al., 2003; Songisepp et al., 2004, 2005; Mikelsaar and Zilmer, 2009).

In recent years, whole-genome sequencing studies of LAB model strains have provided significant insights into the molecular mechanisms by which these bacteria affect biological processes. The principal objective of this study was to investigate the transgalactosylation properties of $\beta$-gal from L. fermentum K4. To this end, the LacLM $\beta$-gal was heterologously expressed and the recombinant protein purified. The amino acid sequences of LacLM and putative active sites were analyzed, and homology with other GH2 $\beta$-gal from various LAB strains was investigated. Our results indicated that the $\beta$-gal from $L$. fermentum $\mathrm{K} 4$ could be used to yield GOS.

\section{MATERIALS AND METHODS}

\section{Bacterial Strains and Culture Conditions}

Lactobacillus fermentum strain K4 (16S rDNA GenBank accession no. EU621851; Table 1) was grown an- aerobically at $37^{\circ} \mathrm{C}$ in standard Lactobacillus de Man, Rogosa, and Sharpe broth (Difco, Detroit, MI) containing $2 \%$ lactose (wt/vol). Escherichia coli Origami $\mathrm{B}$ (DE3) (Table 1) was grown at $37^{\circ} \mathrm{C}$ under aeration in Luria-Bertani broth, supplemented with $100 \mu \mathrm{g} /$ $\mathrm{mL}$ ampicillin and $30 \mu \mathrm{g} / \mathrm{mL}$ kanamycin for plasmid maintenance.

\section{Gene Cloning and Vector Construction}

Chromosomal DNA was extracted from L. fermentum K4 using the TIANamp bacteria genomic DNA extraction kit (Tiangen, Beijing, China). Amplification primers for the lacL and lacM genes encoding $\beta$-gal were designed according to the complete genome sequences of L. fermentum IFO 3956 (GenBank accession no. AP008937) and L. fermentum CECT 5716 (GenBank accession no. CP002033; Table 2). Amplification of the lacLM genes using Lf22b-F and Lf22b-R primers resulted in introduction of $\left(5^{\prime}\right) \mathrm{NcoI}$ and $\left(3^{\prime}\right)$ XhoI restriction enzyme recognition sites, respectively. Likewise, amplification of the large subunit (lacL) gene using LfDuetL-F and LfDuetL-R primers introduced $\left(5^{\prime}\right)$ BamHI and $\left(3^{\prime}\right)$ PstI sites, and amplification of the small subunit (lacM) gene using LfDuetM-F and LfDuetM-R primers introduced $\left(5^{\prime}\right) \mathrm{NdeI}$ and $\left(3^{\prime}\right) \mathrm{Bg} I \mathrm{II}$ sites.

Expression vectors pETDuet-1 and pET-22b(+) (Novagen, Darmstadt, Germany) were restructured with digested PCR products of lacL and lacLM genes, respectively, to generate pDuetL and p22bLM. Subsequently, pDuetL was used to construct the pDuetLM plasmid containing the complete lacLM genes. The restructured plasmids (Table 1) were confirmed by restriction enzyme digestion and sequencing.

\section{Expression and Purification}

The recombinant plasmids p22bLM, pDuetL, and pDuetLM were transformed into E. coli Origami B 
Table 2. Sequences of the primers used in this study

\begin{tabular}{|c|c|c|c|c|c|}
\hline Primer & $\begin{array}{l}\text { Target } \\
\text { fragment }\end{array}$ & $\begin{array}{c}\text { Annealing } \\
\text { temperature }\left({ }^{\circ} \mathrm{C}\right)\end{array}$ & $\begin{array}{l}\text { Size } \\
\text { (bp) }\end{array}$ & $\begin{array}{l}\text { Restriction } \\
\text { enzyme }\end{array}$ & Sequence $^{1}\left(5^{\prime}\right.$ to $\left.3^{\prime}\right)$ \\
\hline$\overline{L f 22 b-F}$ & lacLM & 61 & 2,838 & NcoI & GCACCATGGAAGCAGAGCTGAAATG \\
\hline Lf22b-R & & & & XhoI & TAGCTCGAGGTTAAGCTCGGGCAC \\
\hline LfDuetL-R & & & & Pst $\mathrm{I}$ & GCGCTGCAGTTTGTGTAATCCATAGT \\
\hline LfDuetM-F & $l a c M$ & 58 & 975 & NdeI & GCTCATATGGATTACACAAATAAGCTG \\
\hline LfDuetM-R & & & & $B g l I I$ & TTGAGATCTGTTAAGCTCGGGCAC \\
\hline
\end{tabular}

${ }^{1}$ Restriction enzyme sites are underlined.

(DE3) for expression. The transformants were grown at $37^{\circ} \mathrm{C}$ in antibiotic-supplemented Luria Bertani medium with shaking until an optical density of 0.5 at $600 \mathrm{~nm}$ was reached. Isopropyl- $\beta$-D-thiogalactoside (IPTG, 1 $\mathrm{m} M$ ) was then added to the culture medium and incubation continued at $25^{\circ} \mathrm{C}$ for $12 \mathrm{~h}$. The induced cells were then harvested by centrifugation at $12,000 \times g$ for 10 min at $4^{\circ} \mathrm{C}$.

The cell pellet was suspended with $50 \mathrm{~m} M$ sodium phosphate buffer ( $\mathrm{pH}$ 6.5) and disrupted by sonication, after which the cell debris was pelleted by centrifugation $\left(16,000 \times g\right.$ for $30 \mathrm{~min}$ at $\left.4^{\circ} \mathrm{C}\right)$. The supernatant was then applied to a His-Trap HP column (GE Healthcare, Uppsala, Sweden) that had been pre-equilibrated with buffer A (20 m $M$ sodium phosphate, $0.5 \mathrm{M} \mathrm{NaCl}, 20$ $\mathrm{m} M$ imidazole, $\mathrm{pH}$ 7.4). Nonspecific adsorbed materials were removed by washing with buffer B $(20 \mathrm{mM}$ sodium phosphate, $0.5 \mathrm{M} \mathrm{NaCl}, 40 \mathrm{~m} M$ imidazole, $\mathrm{pH}$ 7.4). The recombinant $\beta$-gal was eluted with elution buffer (20 m $M$ sodium phosphate, $0.5 M \mathrm{NaCl}, 500 \mathrm{~m} M$ imidazole, $\mathrm{pH}$ 7.4). The active fractions were desalted and collected by ultrafiltration with Amicon Ultra-4 (Millipore, Billerica, MA). The concentration of protein was determined by the Bradford method using BSA as standard (Bradford, 1976). The expression level and purity of recombinant $\beta$-gal were evaluated by resolution by $12 \%$ SDS-PAGE and compared with a protein molecular weight marker (TaKaRa, Shiga, Japan) after visualization with Coomassie Brilliant Blue staining.

\section{Enzyme Assays}

$\beta$-Galactosidase activity was determined using $o$-nitrophenyl- $\beta$-D-galactopyranoside ( $\boldsymbol{o N P G}$ ) and lactose as the substrates. The $o \mathrm{NPG}$ reaction was carried out in $100 \mu \mathrm{L}$ of $50 \mathrm{~m} M$ sodium phosphate buffer $(\mathrm{pH}$ 6.5) containing $40 \mu \mathrm{L}$ of $20 \mathrm{~m} M o \mathrm{NPG}$ and $10 \mu \mathrm{L}$ of diluted enzyme solution. After $10 \mathrm{~min}$ of incubation at reaction temperature, $100 \mu \mathrm{L}$ of $1 M \mathrm{Na}_{2} \mathrm{CO}_{3}$ was added to terminate the reaction. Activity of $\beta$-gal was determined by the amount of $o$-nitrophenol $(\boldsymbol{o N P})$ released, as measured by absorbance at $405 \mathrm{~nm}$ on a microplate reader (Bio-Rad Laboratories, Hercules, CA). One unit of $o \mathrm{NPG}$ activity was defined as the amount of enzyme releasing one micromole of $o \mathrm{NP}$ per minute under the described conditions.

The lactose substrate reaction was initiated by adding $50 \mu \mathrm{L}$ of diluted enzyme solution to $150 \mu \mathrm{L}$ of 50 $\mathrm{m} M$ sodium phosphate buffer $(\mathrm{pH} 6.5)$ with $200 \mathrm{mM}$ lactose. After $10 \mathrm{~min}$ of incubation at reaction temperature, the reaction was stopped by heating at $100^{\circ} \mathrm{C}$ for 5 min. Activity of $\beta$-gal was determined by measuring the amount of D-glucose released using a commercially available glucose oxidase kit (Biosino, Beijing, China) and reading absorbance at $490 \mathrm{~nm}$. One unit of lactase activity was defined as the amount of enzyme releasing one micromole of D-glucose per minute under the given conditions.

\section{Characterization of the Recombinant $\beta$-gal Enzyme}

$p H$ and Temperature Dependence of Activity and Stability. Both oNPG and lactose assays were variably performed so as to determine the optimum $\mathrm{pH}$ and temperature of the respective enzyme activity. The optimum $\mathrm{pH}$ was determined for the range of $\mathrm{pH}$ from 2.5 to 11.0 by using $50 \mathrm{mM}$ McIlvaine buffer (pH 2.5-5.5), $50 \mathrm{~m} M$ sodium phosphate buffer ( $\mathrm{pH} 5.5-8.0$ ), or $50 \mathrm{~m} M$ glycine- $\mathrm{NaOH}$ buffer (pH 8.5-11.0). The optimum temperature was determined by measuring the respective enzyme activity over a range from 20 to $70^{\circ} \mathrm{C}$ (Juajun et al., 2011). All other assay conditions remained unchanged.

The release of $o \mathrm{NP}$ from $o \mathrm{NPG}$ was measured to determine $\mathrm{pH}$ and thermal stability. For determination of $\mathrm{pH}$ stability, the enzyme samples were diluted with buffers of various $\mathrm{pH}$ values and incubated at $4^{\circ} \mathrm{C}$ for 3 d. Temperature stability was determined by incubating at various temperatures in a range from 4 to $55^{\circ} \mathrm{C}$ for more than $120 \mathrm{~min}$. The samples were separated at the desired time intervals, and the residual activity was measured under standard assay conditions. 
A

L. reuteri|ABQ82558| $\square$ WS LGNESYAG KPFMECEYMHDMGNS L. acidophilus|AAV43287| $\square$ WS LGNESYAG KPFMECEYMHDMGNS

L. helveticus|ADX69842| $\square$ WS LGNESYAG KPFMECEYMHDMGNS L. johnsonii|EEJ59848| $\square$ WS LGNESYAG L. plantarum|CAD65569| $\square$ WS LGNESYAG KPFLECEYMHDMGNS KPFLDCEYMHDMGNS L. sakei|CAI56018| $\square$ WS LGNESYAG KPF I LCEYMHDMGNS L. delbrueckii|ACE06986| $\square$ WS LGNESYAG B. longum|EEI80881| $\square$ WS LGNESY AG KPF I SVEYAHAMGNS KPY I S CEYMHAMGNS L. fermentum K4|HQ727550| $\otimes$ WS VGNESYAG L. salivarius|ADJ78641| $\square$ WS CG NESYAG KPF IECEYMHSMGNS KPY I SCEYMHSMGNS S. thermophilus|AAV61011| $\square$ WS CGNESYAG L. rhamnosus|CAR86365| $\square$ WS LGNESDFG L. lactis|AAK06078| $\square$ WS LGNESGYG E. coli|BAI53855| $\square$ WS LGNESGHG KPYISCEYMHTMGNS KPHI LCEYYAHSMGNG RPLI LCEYYADMGNS RPLI LCEYAHAMGNS Consensus WS LGNESYAG KPF I ECEYMHDMGNS

B

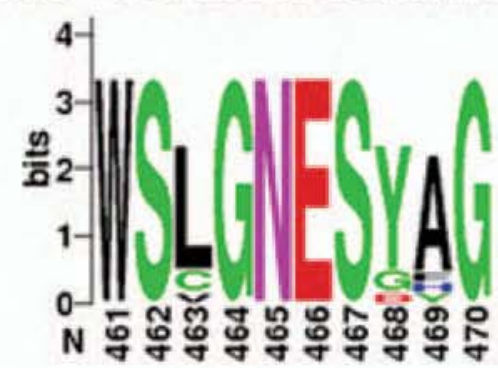

(a)

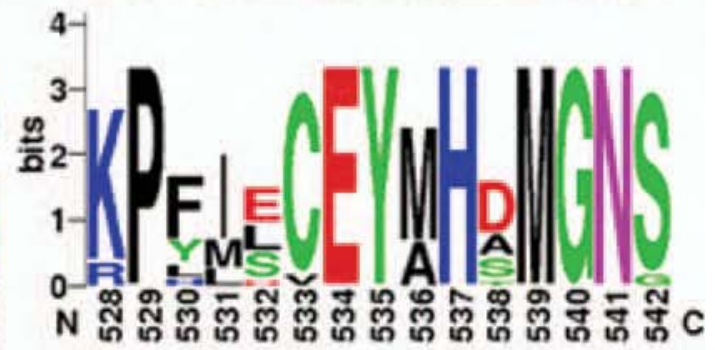

(b)

Figure 1. Multiple alignments of the possible active sites (A) and conservative frequency (B) of $\beta$-galactosidases of different species (genera: L. = Lactobacillus spp., B. = Bifidobacterium spp., S. = Streptococcus spp., and E. = Escherichia). GenBank accession numbers follow the species names. Conserved catalytic amino acids proposed to be the key residues in the active sites are indicated with black arrows. Color version available in the online PDF.

Determination of Kinetic Parameters. Kinetic parameters were evaluated by performing the $o \mathrm{NPG}$ and lactose assays at $30^{\circ} \mathrm{C}$ using $50 \mathrm{~m} M$ sodium phosphate buffer $(\mathrm{pH} 6.5)$ with substrate concentrations ranging from 0.5 to $22 \mathrm{mM}$ for $o \mathrm{NPG}$ and from 1 to $600 \mathrm{~m} M$ for lactose (Nguyen et al., 2006).

Effect of Various Cations and Reagents. To study the effect of various cations and reagents on the activity of $\beta$-gal, the enzyme samples were assayed with aqueous solution containing $20 \mathrm{~m} M o \mathrm{NPG}$ at the optimum temperature for $10 \mathrm{~min}$ in the presence of various cations and reagents added at a final concentration of 5 $\mathrm{m} M$, or at $15 \%$ (vol/vol) for ethanol and glycerol. The measured activities were compared with the activity of the enzyme solution under the same conditions but without added cations or reagents.

\section{Formation of GOS}

Cell extracts were incubated for $48 \mathrm{~h}$ at $45^{\circ} \mathrm{C}$ in $50 \mathrm{~m} M$ sodium phosphate buffer $(\mathrm{pH}$ 6.5) with either lactose solution (20\% or $40 \%$, wt/vol) or milk containing $5 \%$ (wt/vol) lactose, respectively. Samples were withdrawn at certain time intervals and immediately heated at $100^{\circ} \mathrm{C}$ for $5 \mathrm{~min}$ to inactivate the enzyme. The compositions of GOS mixtures were analyzed using thin-layer chromatography (TLC) and an HPLC system. The TLC was carried out on silica-gel 60 plates 


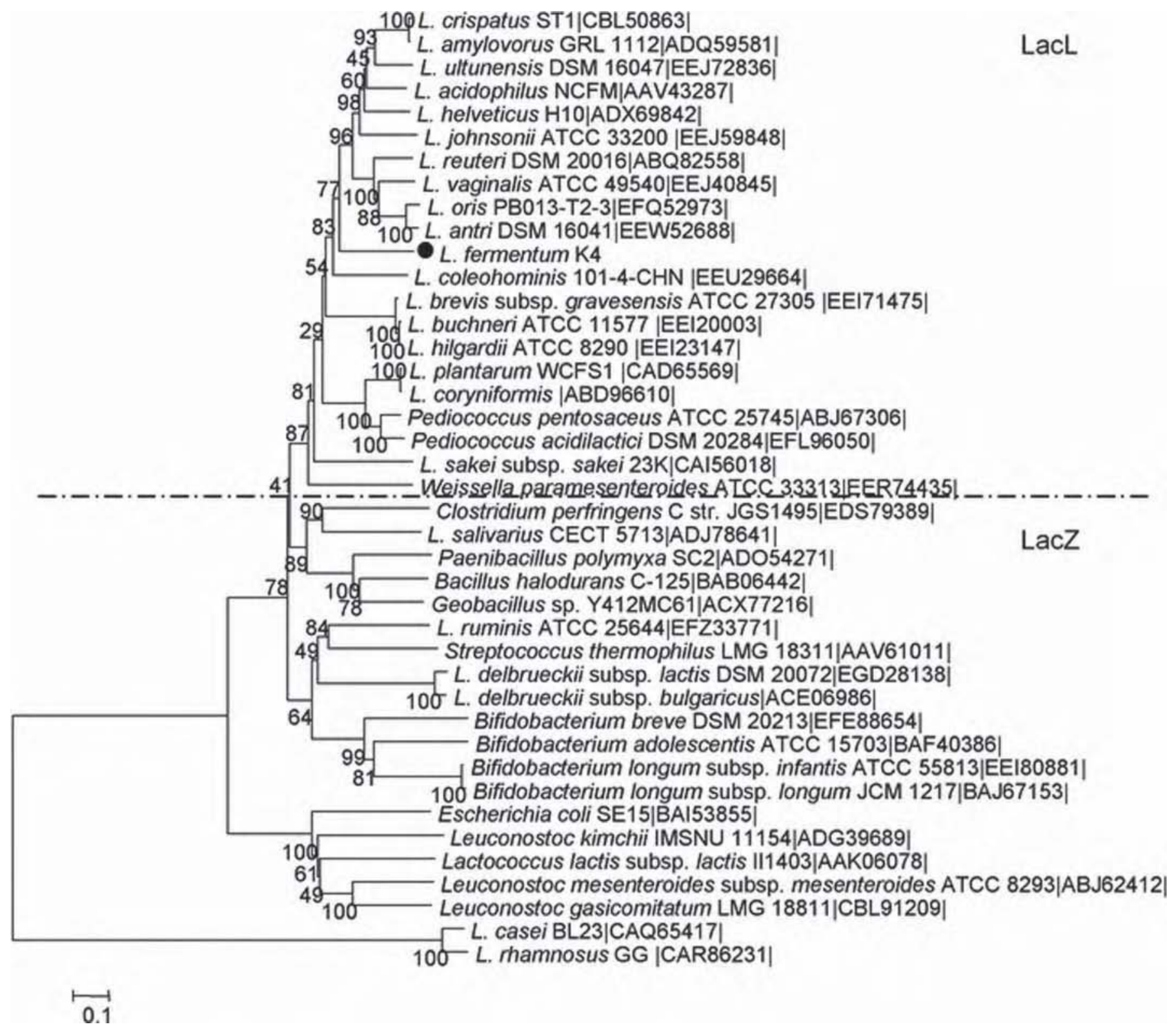

Figure 2. Phylogenetic tree of $\beta$-galactosidase from some lactic acid bacteria (where L. = Lactobacillus). Lactobacillus fermentum K4 is marked with a black circle. GenBank accession numbers follow the species names. The $\beta$-galactosidases above the dotted line pertain to the LacLM type, and those below the dotted line pertain to the LacZ type, except the $\beta$-galactosidases of glycoside hydrolase group (GH) 42 from Lactobacillus rhamnosus GG and Lactobacillus casei BL23.

(Merck, Darmstadt, Germany) in a solvent composed of $n$-butanol: $n$-propanol:ethanol:water (2:3:3:2, vol/ $\mathrm{vol} / \mathrm{vol} / \mathrm{vol}$ ), as described previously (Splechtna et al., 2006). For further analysis of GOS, the samples were diluted appropriately, filtered, and injected into the HPLC system on a column of Aminex HPX 87H (Bio-Rad Laboratories) at $50^{\circ} \mathrm{C}$ using $5 \mathrm{mM} \mathrm{H}_{2} \mathrm{SO}_{4}$ solution as the mobile phase $(0.3 \mathrm{~mL} / \mathrm{min})$ and refractive index detection. The yield of GOS was calculated by the previously described method (Jørgensen et al., 2001).

\section{Nucleotide Sequence Accession Numbers}

The genes of $l a c L$ and $l a c M$ were submitted to the GenBank database under accession numbers HQ727550 and HQ727551, respectively.

\section{RESULTS}

\section{Sequence Analysis of $\beta$-gal from L. fermentum K4}

The L. fermentum K4 genome sequences of lacL and lacM share an overlapping region of 17 nucleotides. 


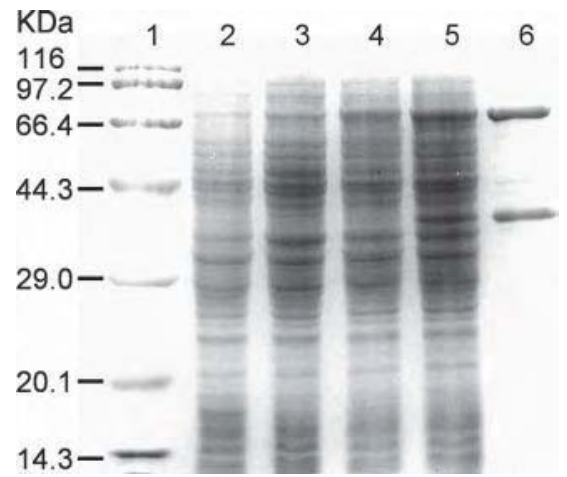

Figure 3. Sodium dodecyl sulfate-PAGE analyses of $\beta$-galactosidase (LacLM) from Lactobacillus fermentum K4 expression in Escherichia coli Origami B (DE3). Lane 1 = protein molecular weight marker; lane $2=$ cells of $E$. coli Origami B (DE3); lane $3=$ cells of $E$. coli containing p22bLM without induction; lanes 4 and $5=$ cells grown with pDuetL (lane 4) and p22bLM (lane 5) for $12 \mathrm{~h}$ with $1 \mathrm{mM}$ isopropyl$\beta$-D-thiogalactoside induction, respectively; lane $6=$ purified protein of $\beta$-galactosidase LacLM.

Sequence alignment by the basis local alignment tool (http://blast.ncbi.nlm.nih.gov/Blast.cgi) revealed that these 2 genes have $99.81 \%$ identity to those published from L. fermentum strains IFO 3956 and CECT 5716. Based on the deduced amino acid sequences of the $\beta$-gal large subunit LacL and small subunit LacM, the theoretical molecular weights were estimated to be 72.29 and $35.8 \mathrm{kDa}$, respectively (http://au.expasy. org/tools/pi_tool.html). The L. fermentum K4 $\beta$-gal resembles the GH2 family members that are classified as LacLM type as opposed to LacZ type (Schwab et al., 2010). The potential active sites in L. fermentum K4 LacLM were identified by comparison with those defined for the other major LAB by using the CLC sequence viewer (Figure 1A) and WebLogo (Figure 1B; http://weblogo.berkeley.edu/logo.cgi). The E. coli LacZ acid/base and nucleophile regions are located at residues Glu461 and Glu537 (Cupples et al., 1990; Gebler et al., 1992; Henrissat and Bairoch, 1993; Hung et al., 2001; Matthews, 2005). These regions were located in L. fermentum K4 LacLM at Glu466 (Figure 1Ba) and Glu534 (Figure 1Bb) and exhibited remarkably high identity with the corresponding ones from E. coli LacZ. However, when the entire AA sequence of L. fermentum K4 LacLM was compared with that of E. coli LacZ, only $31.66 \%$ identity was observed.

Phylogenetic trees were constructed for LacL and LacM of L. fermentum K4 using MEGA 5 software (www.megasoftware.net) with the bootstrap method and using all of the putative $\beta$-galactosidases discovered thus far in Lactobacillus spp. and some of the LAB strains that are prevalent in food manufacturing. Figure 2 shows the LacL phylogenetic tree of $L$. fermentum
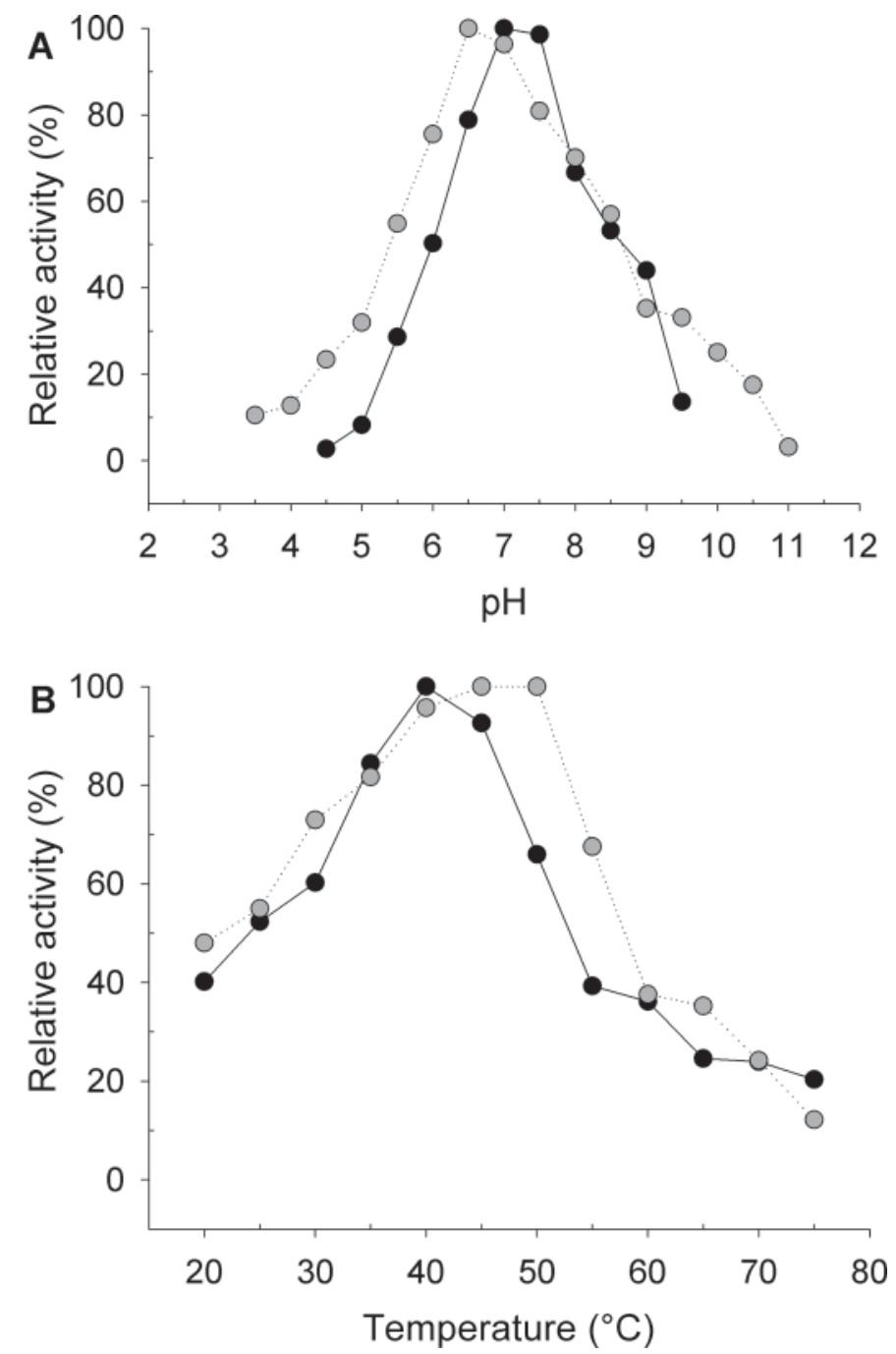

Figure 4. $\mathrm{pH}(\mathrm{A})$ and temperature (B) optima of $\beta$-galactosidase from Lactobacillus fermentum K4 using o-nitrophenyl- $\beta$-Dgalactopyranoside (black circles) and lactose (gray circles) as the substrates, respectively. For all the graphs, the values are the mean of 3 determinations.

K4. Both LacL and LacM (data not shown) were most closely related to the $\beta$-gal from other Lactobacillus spp.

\section{Expression of $\beta$-gal from L. fermentum in E. coli}

The $\beta$-gal LacLM from $L$. fermentum K4, which is encoded by the lacLM operon, was amplified and cloned into pET-22b(+), resulting in the p22bLM expression vector. To study the detailed characteristics of this strain-specific $\beta$-gal, the large subunit gene lacL was cloned and expressed as an IPTG-inducible recombinant protein (as described in Materials and Methods). Sodium dodecyl sulfate-PAGE analysis of the $\beta$-gal samples at various steps of the expres- 

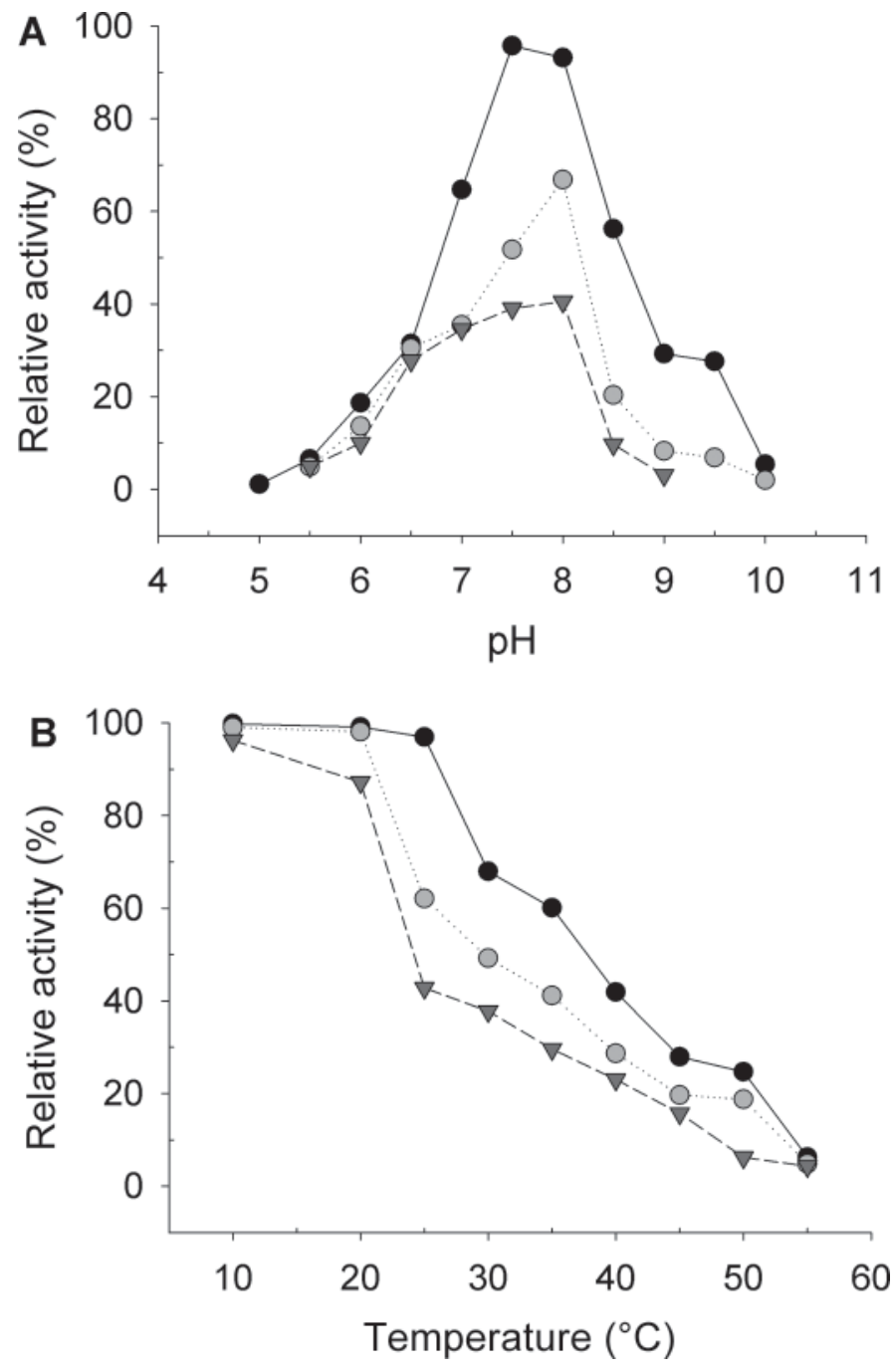

Figure 5. $\mathrm{pH}(\mathrm{A})$ and temperature (B) stability of $\beta$-galactosidase from Lactobacillus fermentum K4. The enzyme was incubated for different periods: A: $24 \mathrm{~h}$ (black circles), $48 \mathrm{~h}$ (gray circles), $72 \mathrm{~h}$ (gray triangles); B: 20 min (black circles), $40 \mathrm{~min}$ (gray circles), $100 \mathrm{~min}$ (gray triangles). For all graphs, the values are the mean of 3 determinations.

sion and purification process are shown in Figure 3. The purified recombinant LacLM consisted of a large subunit and a small subunit, which were estimated to be approximately $\sim 72$ and $35 \mathrm{kDa}$, respectively (lane $6)$. The large subunit LacL, which was encoded by the lacL gene from vector pDuetL, was expressed (lane 4) with no activity. However, the whole protein LacLM encoded by the recombinant plasmid pDuetLM (and generated by inserting the $l a c M$ gene before the S-tag of pDuetL) was active.

\section{Properties of $\beta$-gal}

The optimal $\mathrm{pH}$ of $\beta$-gal LacLM were determined to be $\mathrm{pH} 6.5$ and 7.0 for lactose and oNPG substrates, respectively (Figure 4A). The enzyme exhibited very low activity outside the range of $\mathrm{pH}$ from 5.5 to 8.5. Optimum temperature was $40^{\circ} \mathrm{C}$ for the transgalactosylation activity with oNPG (Figure $4 \mathrm{~B}$ ) and 45 to $50^{\circ} \mathrm{C}$ for lactose hydrolysis. The kinetic parameters $K_{\mathrm{m}}$ (Michaelis constant) and $V_{\max }$ (maximum rate) of the purified enzyme were determined to be approximately $1.31 \mathrm{mM}$ and $184.4 \mu \mathrm{mol} \cdot \mathrm{min}^{-1} \cdot \mathrm{mg}^{-1}$ for $o \mathrm{NPG}$, and $27 \mathrm{mM}$ and $41 \mu \mathrm{mol} \cdot \mathrm{min}^{-1} \cdot \mathrm{mg}^{-1}$ for lactose hydrolysis.

The purified recombinant $\beta$-galactosidase protein was determined to be more stable at $\mathrm{pH} 8.0$ after $3 \mathrm{~d}$ of incubation at $4^{\circ} \mathrm{C}$ (Figure 5A), which was distinct from the optimal $\mathrm{pH}$. The protein was also found to retain about $40 \%$ of its enzyme activity in neutral $\mathrm{pH}$ after incubation for $72 \mathrm{~h}$. Thermal stability was observed in the range of 10 to $20^{\circ} \mathrm{C}$ (Figure 5B), and 35 to $50 \%$ of the maximum activity was retained after incubation in the temperature range for $2 \mathrm{~d}$ (data not shown). Incubation at $55^{\circ} \mathrm{C}$ inactivated the enzyme within 20 min (Figure 5B).

\section{Effect of Various Cations and Reagents}

The activity of $L$. fermentum K4 recombinant $\beta$-gal was enhanced upon exposure to $15 \%$ (wt/vol) ethanol and $5 \mathrm{mM} \mathrm{Na}{ }^{+}, \mathrm{K}^{+}$, and $\mathrm{Mg}^{2+}$ (Figure 6). The reagent dithiothreitol had almost no effect on enzymatic activity. The activity was moderately inhibited by glycerol, 2-mercaptoethanol, and urea, and was clearly inhibited by $\mathrm{Fe}^{2+}, \mathrm{Mn}^{2+}$, and $\mathrm{Zn}^{2+}$. Glutathione, $\mathrm{Cu}^{2+}$, and $\mathrm{Fe}^{3+}$ completely deactivated the enzyme. Thus, the cations $\mathrm{K}^{+}$and $\mathrm{Mg}^{2+}$ were considered and applied as cofactors to enhance the efficiency of $L$. fermentum $\beta$-gal.

\section{Bioconversion of Lactose}

Certain microbial $\beta$-gal can mediate the transfer of their hydrolyzed galactose products onto lactose to yield GOS (Panesar et al., 2006; Park and Oh, 2010). The $\beta$-gal LacLM from $L$. fermentum K4 exhibits such transgalactosylation activities. During lactose conversion, we observed that the transgalactosylation reaction was rapidly initiated, as demonstrated by the formation of GOS in $0.5 \mathrm{~h}$ (Figure 7A). The weight of GOS as a percentage of the total sugars in the reaction mixture was determined by HPLC. The value reached a maximum of $37 \%$ when the incubation involving $50 \mathrm{mM}$ sodium phosphate buffer $(\mathrm{pH} 6.5)$ at $45^{\circ} \mathrm{C}$ with $40 \%$ (wt/ vol) lactose solution was extended to $9 \mathrm{~h}$. Beyond $9 \mathrm{~h}$, however, hydrolysis prevailed over transgalactosylation, and the total amounts of GOS trended downwards, accompanied by an increase in galactose content (Figure 7B). When a lower lactose content solution was used (as in milk), the amount of bioconverted GOS was less. 


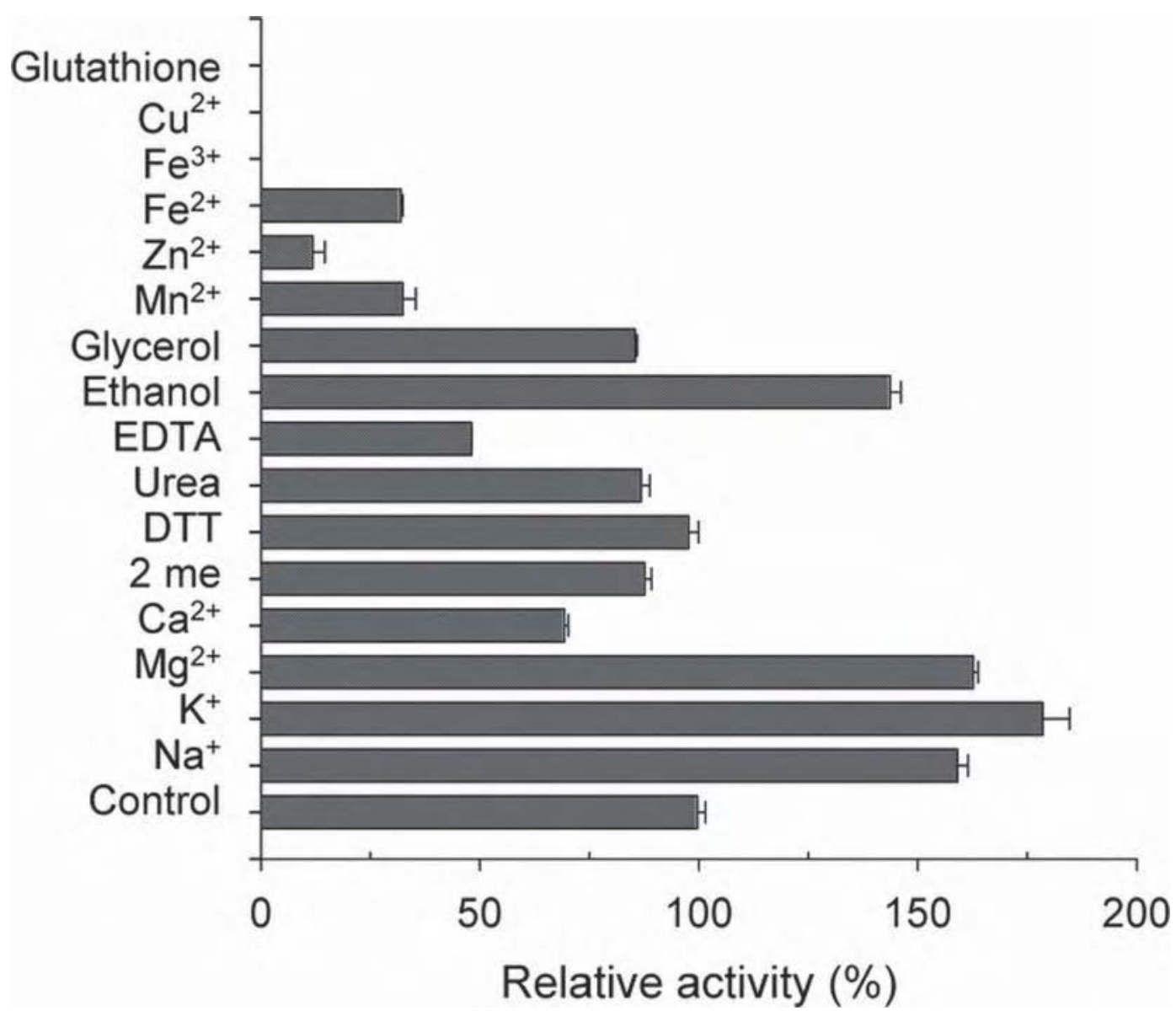

Figure 6. Effect of various cations and reagents on the activity of $\beta$-galactosidase from Lactobacillus fermentum K4. DTT = dithiothreitol.

Likewise, as the lactose concentration was increased in the reaction solution, more and larger GOS were produced (Figure 7). This result was consistent with that from a previous report (Albayrak and Yang, 2002).

\section{DISCUSSION}

The $\beta$-gal from $L$. fermentum strain K4 was cloned, expressed, purified, and analyzed to determine its distinctive enzymatic properties and indicate its potential as a manipulable molecular tool for bioconversion of GOS. The recombinant $\beta$-gal showed a broad $\mathrm{pH}$ optimum and stability around neutral $\mathrm{pH}(6.5-8.5)$, preferably utilized lactose between 45 and $50^{\circ} \mathrm{C}$, and was quickly inactivated at $55^{\circ} \mathrm{C}$. The cations $\mathrm{Na}^{+}, \mathrm{K}^{+}$, and $\mathrm{Mg}^{2+}$ improved enzymatic activity, consistent with findings from previous studies on other LacLM-type $\beta$-gal (Nguyen et al., 2006, 2007; Iqbal et al., 2010). The effect of $\mathrm{Mn}^{2+}$ was especially noteworthy, because it increases $\beta$-gal activity from both L. fermentum K4 and Lactobacillus plantarum WCFS1 (Iqbal et al., 2010), but inhibits that from Lactobacillus acidophilus
(Nguyen et al., 2007). Another interesting finding was that ethanol was a stimulator of $\beta$-gal LacLM enzyme, a finding yet to be reported with any other of the LAB. This may be a reflection of the relatively broad range of environmental niches in which $L$. fermentum is known to function; it is possible that a symbiotic relationship evolved with other ethanol-producing strains, such as Saccharomyces cerevisiae or Zymomonas mobilis. In addition, the types and total amounts of GOS that were produced by the L. fermentum LacLM were mediated by the concentration of lactose solution, not the temperature or $\mathrm{pH}$.

The $\beta$-gal enzyme is known to catalyze the hydrolysis and transglycosylation of its substrates through a double-displacement reaction involving both galactosylation and degalactosylation steps (Brás et al., 2010). The preference for transglycosylation activity can be enhanced by exposure to high concentrations of lactose, as demonstrated by measuring the difference between glucose and galactose products that arise from specific reaction conditions. In our study, we observed that the greatest yield of GOS was achieved when the differ- 
A
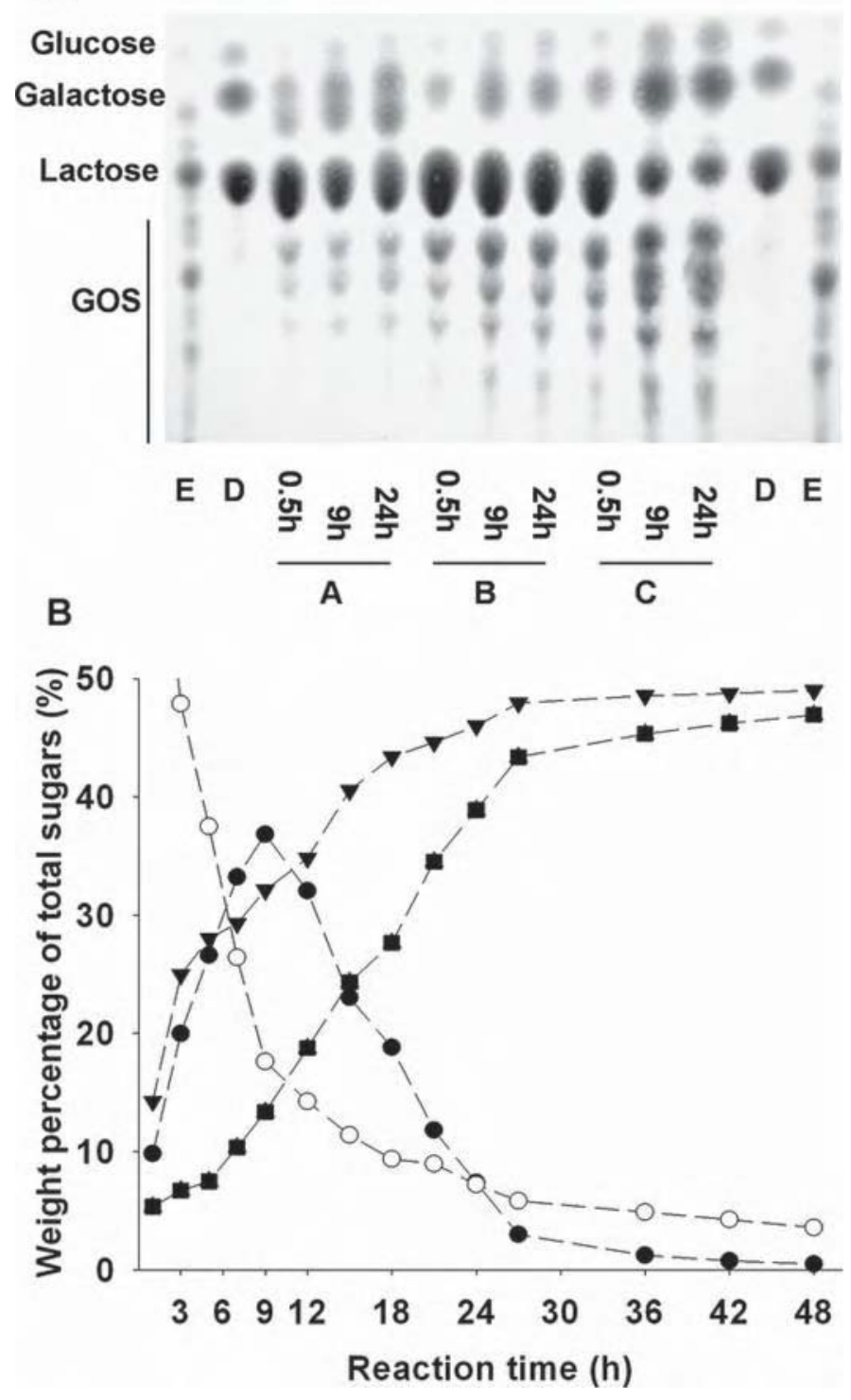

Figure 7. Thin layer chromatography (A) and HPLC (B) analysis of transgalactosylation products. (A) $\mathrm{A}=$ milk substrate; $\mathrm{B}=20 \%$ lactose solution; $\mathrm{C}=40 \%$ lactose solution; $\mathrm{D}=$ standard substance; $\mathrm{E}=$ commercial galacto-oligosaccharides (GOS). (B) The enzyme was incubated in $50 \mathrm{~m} M$ sodium phosphate buffer $(\mathrm{pH} 6.5)$ at $45^{\circ} \mathrm{C}$ with $40 \%$ (wt/vol) lactose solution: lactose $(\bigcirc)$, galactose $(\boldsymbol{\square})$, glucose $(\boldsymbol{\Delta})$ and GOS $(\bullet)$. For all graphs, the values are the mean of 3 determinations.

ence value was greatest. Fortunately, the recombinant LacLM was able to bioconvert GOS from milk lactose (which exists at very low concentrations).

As mentioned above, the $\beta$-gal from $L$. fermentum $\mathrm{K} 4$ is composed of a large subunit (LacL) and a small subunit (LacM) and belongs to the GH2 family of carbohydrate-active enzymes. Most Lactobacillus strains contain the LacLM type $\beta$-gal, and some LAB that are involved in fermentation (particularly in the food industry) pertain to the LacZ type, such as Bifidobacterium spp., Lactococcus spp., and Streptococcus spp. (Hung et al., 2001; Jørgensen et al., 2001; Hung and Lee, 2002; Lamoureux et al., 2002; Hsu et al., 2007). Phylogenetic analysis revealed that both the large subunit LacL and small subunit LacM of L. fermentum K4 $\beta$-galactosidase had high homology with most of the $\beta$-galactosidase from other Lactobacillus spp. It should be noted that the probiotic Lactobacillus rhamnosus GG contains the $\beta$-gal ebgA (CAR86365) and bgaC (CAR86231), which belong to GH2 and GH42, respectively, which is distinct from the other Lactobacillus spp.. Furthermore, $\beta$-gal from the genus Pediococcus were also represented in the LacLM group. In general, 4 subgeneric groups were generated based on the phylogenies of Lactobacillus. Lactobacillus fermentum was classified into group B, which contained some Lactobacillus spp. strains, such as Lactobacillus salivarius, $L$. plantarum, Lactobacillus reuteri, Lactobacillus brevis, Lactobacillus antri, and even Pediococcus pentosaceus (Claesson et al., 2008).

Through this study, we were able to confirm that the $L$. fermentum $\beta$-gal would be functionally activated in its complete form, including both the small subunit LacM and the large subunit LacL. Because LacL was not active in the absence of LacM, we presumed that LacM might be the unit essentially mediating the activity of LacLM type $\beta$-gal. Interestingly, the functional LacM subunit from L. antri DSM $16041 \beta$-gal (EEW52689) is only 229 AA long, unlike most of the other Lactobacillus $\beta$-gal that are approximately 320 AA long. This suggested to us that L. fermentum $\beta$-galactosidase activity may be manipulable by altering (truncating) the LacM sequence. This strategy, if successful (experiments ongoing in our laboratory), would be a useful method for customizing the enzyme according to specific industrial needs. In addition to the lower lactose concentration, the inhibition of glucose seriously restricted the production of GOS, and we presume that inhibition could be reduced through immobilization of the substrate or structural modification of the enzyme at the product-binding site (Kim et al., 2004; Mateo et al., 2004; Park and Oh, 2010). Thus, the findings from this study will aid future research focused on enhancing the transgalactosylation activity of $\beta$-gal and developing more efficient enzymes to generate high yields of GOS.

\section{ACKNOWLEDGMENTS}

Financial support of this work was supported by Program for Changjiang Scholars and Innovative Research Team in Northeast Agricultural University (IRT0959), Harbin, China. 


\section{REFERENCES}

Albayrak, N., and S. T. Yang. 2002. Production of galacto-oligosaccharides from lactose by Aspergillus oryzae $\beta$-galactosidase immobilized on cotton cloth. Biotechnol. Bioeng. 77:8-19.

Bradford, M. M. 1976. A rapid and sensitive method for the quantitation of microgram quantities of protein utilizing the principle of protein-dye binding. Anal. Biochem. 72:248-254.

Brás, N. F., P. A. Fernandes, and M. J. Ramos. 2010. QM/MM studies on the $\beta$-galactosidase catalytic mechanism: Hydrolysis and transglycosylation reactions. J. Chem. Theory Comput. 6:421-433.

Calderon Santoyo, M., G. Loiseau, S. R. Rodriguez, and J. P. Guyot. 2003. Study of starch fermentation at low $\mathrm{pH}$ by Lactobacillus fermentum Ogi E1 reveals uncoupling between growth and $\alpha$-amylase production at $\mathrm{pH}$ 4.0. Int. J. Food Microbiol. 80:77-87.

Cantarel, B. L., P. M. Coutinho, C. Rancurel, T. Bernard, V. Lombard, and B. Henrissat. 2009. The Carbohydrate-Active EnZymes database (CAZy): An expert resource for glycogenomics. Nucleic Acids Res. 37(Database issue):D233-D238.

Claesson, M. J., V. S. Douwe, and P. W. O'Toole. 2008. Lactobacillus phylogenomics - Towards a reclassification of the genus. Int. J. Syst. Evol. Microbiol. 58:2945-2954.

Cupples, C. G., J. H. Miller, and R. E. Huber. 1990. Determination of the roles of Glu-461 in $\beta$-galactosidase (Escherichia coli) using site-specific mutagenesis. J. Biol. Chem. 265:5512-5518.

Gebler, J. C., R. Aebersold, and S. G. Withers. 1992. Glu-537, not Glu461 , is the nucleophile in the active site of (lacZ) $\beta$-galactosidase from Escherichia coli. J. Biol. Chem. 267:11126-11130.

Henrissat, B., and A. Bairoch. 1993. New families in the classification of glycosyl hydrolases based on amino acid sequence similarities. Biochem. J. 293:781-788.

Hsu, C. A., R. C. Yu, S. L. Lee, and C. C. Chou. 2007. Cultural condition affecting the growth and production of $\beta$-galactosidase by Bifidobacterium longum CCRC 15708 in a jar fermenter. Int. J. Food Microbiol. 116:186-189.

Hung, M. N., and B. Lee. 2002. Purification and characterization of a recombinant $\beta$-galactosidase with transgalactosylation activity from Bifidobacterium infantis HL96. Appl. Microbiol. Biotechnol. $58: 439-445$.

Hung, M. N., Z. Xia, N. T. Hu, and B. H. Lee. 2001. Molecular and biochemical analysis of two $\beta$-galactosidases from Bifidobacterium infantis HL96. Appl. Environ. Microbiol. 67:4256-4263.

Iqbal, S., T. H. Nguyen, T. T. Nguyen, T. Maischberger, and D. Haltrich. 2010. $\beta$-galactosidase from Lactobacillus plantarum WCFS1: Biochemical characterization and formation of prebiotic galactooligosaccharides. Carbohydr. Res. 345:1408-1416.

Jørgensen, F., O. C. Hansen, and P. Stougaard. 2001. High-efficiency synthesis of oligosaccharides with a truncated $\beta$-galactosidase from Bifidobacterium bifidum. Appl. Microbiol. Biotechnol. 57:647-652.

Juajun, O., T. H. Nguyen, T. Maischberger, S. Iqbal, D. Haltrich, and M. Yamabhai. 2011. Cloning, purification, and characterization of $\beta$-galactosidase from Bacillus licheniformis DSM 13. Appl. Microbiol. Biotechnol. 89:645-654

Kim, C. S., E. S. Ji, and D. K. Oh. 2004. A new kinetic model of recombinant $\beta$-galactosidase from Kluyveromyces lactis for both hydrolysis and transgalactosylation reactions. Biochem. Biophys. Res. Commun. 316:738-743.

Knol, J., P. Scholtens, C. Kafka, J. Steenbakkers, S. Gross, K. Helm, M. Klarczyk, H. Schopfer, H. M. Bockler, and J. Wells. 2005. Colon microflora in infants fed formula with galacto- and fructooligosaccharides: More like breast-fed infants. J. Pediatr. Gastroenterol. Nutr. 40:36-42.

Lamoureux, L., D. Roy, and S. F. Gauthier. 2002. Production of oligosaccharides in yogurt containing bifidobacteria and yogurt cultures. J. Dairy Sci. 85:1058-1069.

Macfarlane, G. T., H. Steed, and S. Macfarlane. 2008. Bacterial metabolism and health-related effects of galacto-oligosaccharides and other prebiotics. J. Appl. Microbiol. 104:305-344.
Mateo, C., R. Monti, B. C. C. Pessela, M. Fuentes, R. Torres, J. M. Guisan, and R. Fernandez-Lafuente. 2004. Immobilization of lactase from Kluyveromyces lactis greatly reduces the inhibition promoted by glucose. Full hydrolysis of lactose in milk. Biotechnol. Prog. 20:1259-1262.

Matthews, B. W. 2005. The structure of E. coli $\beta$-galactosidase. C. R. Biol. 328:549-556.

Mikelsaar, M., and M. Zilmer. 2009. Lactobacillus fermentum ME-3An antimicrobial and antioxidative probiotic. Microb. Ecol Health Dis. 21:1-27.

Nguyen, T. H., B. Splechtna, S. Krasteva, W. Kneifel, K. D. Kulbe, C. Divne, and D. Haltrich. 2007. Characterization and molecular cloning of a heterodimeric $\beta$-galactosidase from the probiotic strain Lactobacillus acidophilus R22. FEMS Microbiol. Lett. 269:136-144.

Nguyen, T. H., B. Splechtna, M. Steinböck, W. Kneifel, H. P. Lettner, K. D. Kulbe, and D. Haltrich. 2006. Purification and characterization of two novel $\beta$-galactosidases from Lactobacillus reuteri. J. Agric. Food Chem. 54:4989-4998.

Onishi, N., and T. Tanaka. 1995. Purification and properties of a novel thermostable galacto-oligosaccharide-producing $\beta$-galactosidase from Sterigmatomyces elviae CBS8119. Appl. Environ. Microbiol. 61:4026-4030.

Otieno, D. O. 2010. Synthesis of $\beta$-galactooligosaccharides from lactose using microbial $\beta$-galactosidases. Comp. Rev. Food Sci. Food Saf. 9:471-482.

Panesar, P. S., R. Panesar, R. S. Singh, J. F. Kennedy, and H. Kumar. 2006. Microbial production, immobilization and applications of $\beta$-D-galactosidase. J. Chem. Technol. Biotechnol. 81:530-543.

Park, A. R., and D. K. Oh. 2010. Galacto-oligosaccharide production using microbial $\beta$-galactosidase: Current state and perspectives. Appl. Microbiol. Biotechnol. 85:1279-1286.

Rabiu, B. A., A. J. Jay, G. R. Gibson, and R. A. Rastall. 2001. Synthesis and fermentation properties of novel galacto-oligosaccharides by $\beta$-galactosidases from Bifidobacterium species. Appl. Environ. Microbiol. 67:2526-2530.

Rastall, R. A., and V. Maitin. 2002. Prebiotics and synbiotics: Towards the next generation. Curr. Opin. Biotechnol. 13:490-496.

Schwab, C., K. I. Sørensen, and M. G. Gänzle. 2010. Heterologous expression of glycoside hydrolase family 2 and $42 \beta$-galactosidases of lactic acid bacteria in Lactococcus lactis. Syst. Appl. Microbiol. 33:300-307.

Songisepp, E., J. Kals, T. Kullisaar, R. Mandar, P. Hutt, M. Zilmer, and M. Mikelsaar. 2005. Evaluation of the functional efficacy of an antioxidative probiotic in healthy volunteers. Nutr. J. 4:22.

Songisepp, E., T. Kullisaar, P. Hütt, P. Elias, T. Brilene, M. Zilmer, and M. Mikelsaar. 2004. A new probiotic cheese with antioxidative and antimicrobial activity. J. Dairy Sci. 87:2017-2023.

Splechtna, B., T. H. Nguyen, M. Steinbock, K. D. Kulbe, W. Lorenz, and D. Haltrich. 2006. Production of prebiotic galacto-oligosaccharides from lactose using $\beta$-galactosidases from Lactobacillus reuteri. J. Agric. Food Chem. 54:4999-5006.

Torres, D. P. M., M. P. F. Gonçalves, J. A. Teixeira, and L. R. Rodrigues. 2010. Galacto-oligosaccharides: Production, properties, applications, and significance as prebiotics. Comp. Rev. Food Sci. Food Saf. 9:438-454.

Tzortzis, G., and J. Vulevic. 2009. Galacto-oligosaccharide prebiotics. Pages 207-244 in Prebiotics and Probiotics: Science and Technology. D. Charalampopoulos and R. A. Rastall, ed. Springer, New York, NY.

Walter, J. 2008. Ecological role of lactobacilli in the gastrointestinal tract: Implications for fundamental and biomedical research. Appl. Environ. Microbiol. 74:4985-4996. 